\title{
Industrial Design: Important History Perceptions, New Applications and Bright Future
}

\author{
Lai Shouliang \\ College of Packaging \& Design \\ Hunan University of Technology \\ Zhuzhou, Hunan, China \\ E-mail:3611869@qq.com
}

\author{
Zhu Liang \\ College of Packaging \& Design \\ Hunan University of Technology \\ Zhuzhou, Hunan, China \\ E-mail:525225549@qq.com
}

\begin{abstract}
Industrial design is very important in human being history. This paper reviewed some special perceptions in its whole processing. And nowadays, many new researches and applications are being used in this field: digital design and manufacture, virtual methods, humanistic principles, etc. In future industrial design will play more and more excellent role. As a design activity in its own right, industrial design deconstructs the meaning of ordinary objects and explores its transformation by adornment and wit. In this context, it can rightfully claim its own research and teaching environment in line with the most demanding academic traditions. Many question the appropriateness of the term 'industrial design' for this emerging field of expertise. However, since meaning is created in interaction, the concept of industrial design is also dynamic and changing. So, instead of changing its name, we believe we should explore the potential of industrial design, as we have tried to do over the last twenty years and have documented in this paper.
\end{abstract} future

Keywords-industrial design; perception; application;

\section{INTRODUCTION}

Industrial design (ID) as a profession derives from the more general discipline of design. Design is a very old profession it simply refers to the way in which craftsmen have been designing and creating objects for millennia. Industrial design, however, is specifically seen as a product of the (first) Industrial Revolution when a single craftsman could no longer be responsible for every stage of the development of a product, from conception to sale, although the division between the creation of the product, the idea, and the manufacturing process had already appeared by the beginning of the sixteenth century when workshops specialized and trade expanded (Heskett, 1980). The use and development of new technology, production techniques and materials in the eighteenth and nineteenth centuries, however, enabled the development of mass production, standardization, modularity and diversification of designs for new target groups. This development also required new forms of collaboration between different experts and new business models to stimulate mass consumption (Forty, 1986).

The first use of the term "industrial design" is often attributed to the industrial designer Joseph Claude Sinel in 1919 (although he himself denied this in interviews), but the discipline predates 1919 by at least a decade. Christopher Dresser is considered the world's first industrial designer. Industrial design's origins lie in the industrialization of consumer products. For instance the Deutscher Werkbund, founded in 1907 and a precursor to the Bauhaus, was a state-sponsored effort to integrate traditional crafts and industrial mass-production techniques, to put Germany on a competitive footing with England and the United States.

\section{SOME IMPORTANT PERCEPTIONS IN INDUSTRIAL DESIGN HISTORY}

The earliest use of the term may have been in The Art Union, A monthly Journal of the Fine Arts, 1839:-Đyce's report to the Board of Trade on foreign schools of Design for Manufactures. Mr. Dyces official visit to France, Prussia and Bavaria for the purpose of examining the state of schools of design in those countries will be fresh in the recollection of our readers. His report on this subject was printed some few months since on the motion of $\mathrm{Mr}$. Hume."

The school of St Peter, at Lyons was founded about 1750 for the instruction of draftsmen employed in preparing patterns for the silk manufacture. It has been much more successful than the Paris school and having been disorganized by the revolution, was restored by Napoleon and differently constituted, being then erected into an Academy of Fine Art: to which the study of design for silk manufacture was merely attached as a subordinate branch. It appears that all the students who entered the school commence as if they were intended for artists in the higher sense of the word and are not expected to decide as to whether they will devote themselves to the Fine Arts or to Industrial Design, until they have completed their exercises in drawing and painting of the figure from the antique and from the living model. It is for this reason, and from the fact that artists for industrial purposes are both well paid and highly considered (as being well instructed men) that so many individuals in France engage themselves in both pursuits."

The practical draughtsman's book of industrial design by Jacques-Eugène Armengaud was printed in 1853.Don't try to create ideas in isolation, in the abstract or by using words alone. Use multiple methods. Draw - whether or not you have drawing talent. Visual representations create new 
insights in the form of -imd maps" that show multidirectional connections that linear verbal descriptions could obscure. Prototypes and drawings help develop ideas faster. Prototypes don't have to be expensive or timeconsuming. In fact, the opposite is better: Put as little time and effort into prototypes as you can and still generate useful feedback and drive an idea forward." Early in the process, prototypes can be very basic - just enough to see if something is viable. Imaging software can help, but, for example, researchers first conceived insulin injection devices" with tools as rudimentary as Legos. Role-playing can be useful. Acting out scenarios using an imagined device can bring its possibilities to life. Virtual worlds" like Second Life allow you to observe people interacting with a virtual version of a new service, such as a specialized hotel, with no actual construction at all. You can make prototypes of concepts or abstractions, like organizational structures, as IDEO did when it had to reorganize following the 2000 dot-com industry crash. Its staffers used computer games, workshops, small group discussions, formal speeches and even dance to produce a company culture better suited to new market realities.

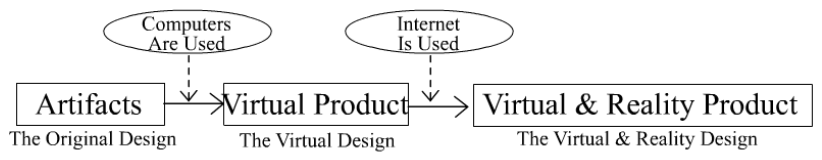

Figure 1. The Development History of Industrial Design

Robert Lepper helped to establish one of the country's first industrial design degree programs at Carnegie Institute of Technology.

\section{THE NEW REASEARCHES AND APPLICATIONS IN INDUSTRIAL DESIGN}

The field of industrial design is changing. That is the message when going to conferences such as TED, the World Design Forum (WDF), ICSID World Design Congress and CHI. According to Stefano Marzano, CEO of Philips Design, we are moving towards a new intellectual renaissance based on humanistic values. Designers are catalysts for change and raise large societal questions (Marzano, 2010). Consequently, the scope of design is changing. It is expanding towards all kind of systems: education, health-care, economic growth, transportation, defense, and political representation. Moreover, the role of designers is changing. Designers are dealing with a creative society in which we are all producers and consumers of value (Nussbaum, 2008).

As stated at the beginning of this chapter, industrial design is concerned with mass production in factories for the broadest market possible. However, given the developments in technology and society, mass production has extended to mass customization, using new production techniques, and the broadest market possible has moved towards a diverse, global society that is no longer based on passive consumers; a society in which people are becoming accomplices in a never-ending design process of highly dynamic, adaptive and intelligent systems, products and services.

We can see a desire for design-driven innovation; that is, we step away from incremental innovation in favors of disruptive innovation, in which disruptive refers to the absence of a well-established frame of reference for users or the market. Not only is the product as such new, but it also enables the creation of radical new meaning for the user, the market and society. The field is moving towards designing open and intelligent systems that evolve during use and have a high level of complexity due to their adaptive, context-dependent and highly dynamic character. Alongside this development, the role of the designer is changing. More and more we see open platforms and design projects in which a variety of people and experts create products. Finally, we see a changing attitude towards growth and development, towards self-directed learning and continuous development as a design professional.

Many question the appropriateness of the term 'industrial design' for this emerging field of expertise. However, since meaning is created in interaction, the concept of industrial design is also dynamic and changing. So, instead of changing its name, we believe we should explore the potential of industrial design, as we have tried to do over the last twenty years and have documented in this paper.

Industrial design is a profession with a distinct culture, which based on the education designers receive, their different values, behaviors, and attitudes. Designers often perceive that their creativity sets them apart from other colleagues in the NPD process, and the cult of the star designer also has hindered integration. As the founder of the Frog Design company has stated: Business people are from Mars, and designers are from Venus". The most visible aspect of this cultural difference is the dress code adopted by so many designers that the black turtleneck has itself become a symbol of the design profession, but the differences go deeper. It has been argued that designers have a particular personality profile, and they have even been called -emotional artists". Their perspective-design thinking - is commonly recognized as being very different from that of other professionals.

Several authors point out that communications between designers and other members of the NPD team are critical. Communication problems between designers and other members of NPD teams are common, and they prevent design from becoming an influential partner in the NPD process. As communications are based on the use of language, it is important to focus on the language used by designers, and why this is different. There are several articles on design that stress that the language of designers is different from other members of NPD teams: Fopics are expressed differently, terminology is used in a different way ..." ". Similarly, Eckert and Stacey found that designers" words can only be understood correctly by people who know what the sources of their design ideas are". The design literature includes a number of articles that have investigated the language used by designers. For example, Dong used semantic analysis to show that groups of designers interacting with each other develop a shared understanding of design. Several studies have focused on the language of designers and communications between designers. Interestingly, such studies have not compared and contrasted these with the vocabularies of managers.

Industrial design is essential for the creation of products that satisfy user needs and aspirations and can be 
differentiated from the competition. However, most companies fail to reap the full benefits of design. This is often due to cultural and language barriers, between design and other functional areas, and barriers to the introduction of industrial design into new-product development (NPD) process. In this paper we show how designers and NPD managers have different perceptions of good" design and the ways to achieve it. We also illustrate the challenges in attempting to introduce industrial design into a structured NPD approach. It is by identifying and tackling these issues that managers can exploit the full potential of design, thus making their companies more innovative and competitive.

\section{THE BRIGHT FUTURE IN INDUSTRIAL DESIGN}

Industrial design studies function and form-and the connection between product, user, and environment. Generally, industrial design professionals work in smallscale design, rather than overall design of complex systems such as buildings or ships. Industrial designers don't usually design motors, electrical circuits, or gearing that make machines move, but they may affect technical aspects through usability design and form relationships. Usually, they work with other professionals such as marketers to identify and fulfill customer needs and expectations.

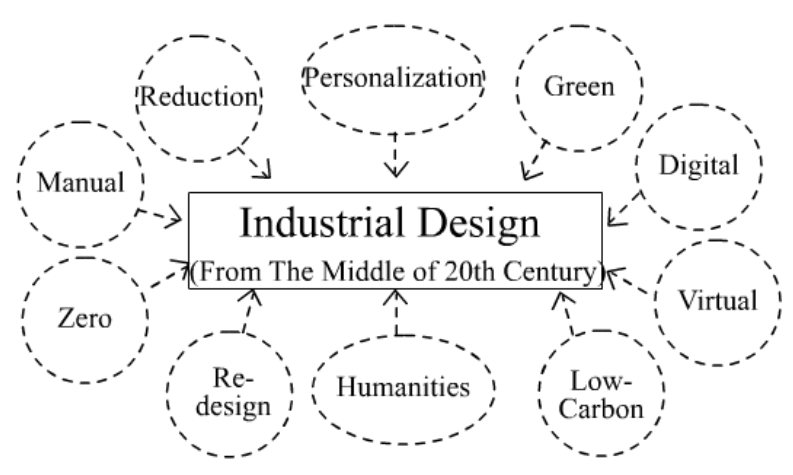

Figure 2. Industrial Design from the Middle of 20th Century

Design, itself, is often difficult to describe to nondesigners and engineers, because the meaning accepted by the design community is not made of words. Instead, the definition is created as a result of acquiring a critical framework for the analysis and creation of artifacts. One of the many accepted (but intentionally unspecific) definitions of design originates from Carnegie Mellon's School of Design, "Design is the process of taking something from its existing state and moving it to a preferred state." This applies to new artifacts, whose existing state is undefined, and previously created artifacts, whose state stands to be improved.

All of the research discussed in the previous paragraph, with its focus on consumer preferences and responses, relates to the -sales" dimension of financial results, which represents a combination of units sold (volume) and selling price. Improving sales-by increasing volume or selling price-is one alternative that can lead to improved financial performance, although it alone is not sufficient to assure improved financial performance at the bottom line. Sales increases must be balanced against any costs required to achieve them. Indeed, senior managers often raise this issue when, despite agreeing that consumers prefer well-designed products, they voice concern about whether the expenditures on industrial design are too high."

Over the past decades, social entrepreneurship has experienced a boom as well. Success stories such as Grameen Bank's micro loans to women, The George Foundation's Women's Empowerment Program, empowering women by providing education and cooperative farming continue to inspire and One Laptop per Child offering an inexpensive laptop designed for children in developing countries. Since social entrepreneurship projects are long-term as compared to product development projects, combining these two very different types of projects could help designers build competencies and produce meaningful results in commercial as well as public areas. For example, when the economy expands, design consultancies could create products or systems for corporations from new technology, cultivating markets and building capabilities. When the economy contracts, designers could phase from commercial products to social challenges, building the social and cultural knowledge base. Working in a for-profit organization teaches one skills that can then be used when working in non-profit, and vice versa.

Building and leveraging unique design competencies together with a broad understanding of what people need and want, through strategy, context and performance metrics is key to creating value. However, to capture more value for oneself, in the end, one needs to understand the economic landscape. Comprehending how designers are being compensated in competitive industries and being able to defend with data the value one has added, then allows one to negotiate a fair share of the pie.

What about the Design Discipline, the organizations and people behind those wonder products? My thoughts will be that it will continue to be more and more difficult to survive if the Design Discipline does not find itself in a strong relationship with branding.

Before we go on, lets now take a quick look at the design discipline, in particular industrial design. It seems these days everyone is talking about design management and creative thinking in business, especially in consumer electronics. Designers, non-designers, engineers, CEOs, management consultants, etc. are all talking, however as Seinfeld always says, not that its anything wrong with that. Not only that, it is also becoming more and more difficult to NOT do good design. Everywhere we go, shops and the media, we are bombarded with fairly good if not great products to buy. Designers are well equip these days with all the right skills and know how to do things right, and the power and speed of the Internet just facilitates it.

It is not surprising to see that a recent AIGA symposium focused on defining Designers in 2015, though targeted more towards Graphic Designers, it did give a route map of great skills and roles designers will play in organizations in the coming years. However in my humble opinion, the viewpoint seems pretty narrow focusing on technical aspects rather than the bigger picture. The successful companies of today (both in design and buyers 
of design circa 2007) have already begun to apply or use such design strategies and management tools. Personally I did not think that the boundaries of the discussion stretched far enough to include leading design management companies such as IDEO (though the symposium did proposed one of IDEO's F" shape characteristics of successful creative and their management), and even management guru Tom Peters as they are in the forefront of such design + creativity management techniques. And these guys have been on their soapbox for a very long time. Perhaps Tom and some chaps from IDEO would have been a great addition to the -drivers" to this discussion.

So if the future is much about continuing about what the best companies are doing now but better, and it seems every one else can eventually catch up and also do an equally good job in design, then what's going to happen to the design discipline? In particular what is going to happen to people whose job is focused on actual design and designing?

\section{SOME PRINCIPLES IN INDUSTRIAL DESIGN}

If we extrapolate this a little more, if good design is good business from China, Korea and to the USA and then Europe, then how can design consultancies and designers be different and rise to the top? On one hand this is a good thing as this means that design has been accepted mainstream as a true strategic competitive advantage for an organization, designers can now rejoice. But the bad thing is good design will now be a given, a commodity. Just like TQM (Total Quality Management) or customer service, good design will become a baseline and expected by consumer, as everyone will be doing some form of it.

In recent years, some of the best products and businesses have been created when local concerns are met with sophisticated solutions. There seems to be a magic formula developing: when city-based designers with an aptitude for technology can identify a unique concern of their neighbors and set out to develop a tailored solution, a beautiful invention is delivered. These advancements eventually spread, and are useful for society at large. For example, prototypes for low-cost DIY Geiger counters appeared in Japan only weeks after the 2011 tsunami and nuclear disaster. Similar sensors made their way into startup Lapka's product: a cord of sensors that plug into your iPhone for measuring radiation, humidity, temperature, and other conditions.

Technology development has become democratized and localized. No longer are tech devices the domain of corporate R\&D houses inside Apple, Samsung, or Nokia. In fact, most of what we've seen in the past few years in New York City are city-based startups developing and selling their own hardware devices. Since these entrepreneurs and their development teams are embedded in the context and user-base they're designing for, the process is quite focused, lean, and iterative.

What has given rise to this new form of R\&D? In the past 10 years, there has been an increase in access to lowcost and easy-to-use prototyping tools for hardware development, including open-source electronics platform Arduino. These tools allow designers and technologists to prototype smart products with just a $\$ 30$ circuit board and some code uploaded from a laptop. Designers can now move beyond ergonomics and manufacturing strategies to developing functional features in their projects. Consider health devices, sensor platforms, traffic counters, and GPS-enabled bike sharing. Coupled with the movement for the quantified-self" (think Jawbone UP Bracelet, Withings bathroom scale, and FitBit), putting inexpensive data sensing and logging capabilities into products is the new status quo. With these advances, the transition from prototype to market-ready product has been made easier.

After development, the product may be launched on crowd funding websites like Kickstarter or Indiegogo, where the product's viability and features are vetted with real users before they even go into production. If the campaigns are successful and funding is reached, online sales of the factory-produced products can be hosted quickly to deliver to relevant customers in neighborhoods (all over the world sometimes) — all without ever touching a store shelf. Other times, the product should be sought after by the corporations, who see the market potential in their existing sales channels. In such a business exchange, the corporation has a potential to save thousands of dollars in R\&D and market research costs as the city-based entrepreneur has likely done all of that. In fact these are requisite activities if the product is to be bootstrapped into a small business.

Speed of development is an important consideration to round this discussion. With the U.S. patent system moving from First-To-Invent to First-To-File on March 16, 2013, the pace of IP development will be given even more priority. In the new patent climate, more small technology inventors might find themselves going head-to-head with corporations in existing and emerging technology device markets.

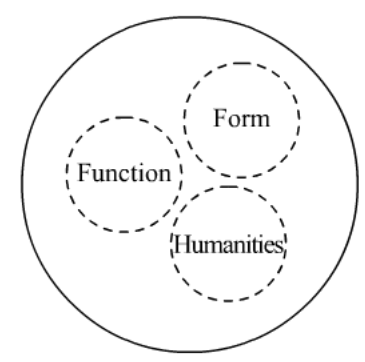

Figure 3. The Core of Design

You'll now find technology development labs inside product design companies from New York to Londonpreviously unheard of locations for technology hardware product development and design. Aside from the company I founded, Tomorrow Lab, other examples of these labs include Smart Design's Interaction Lab, and Berg London. These small labs mean that the development process is focused on creating the minimum viable product', wrapped in a beautiful design, wrapped in a well-branded story.

In an already competitive environment, the democratization and localization of new product development has increased the stakes between corporate offices and community-driven technology labs. Whatever the result, the end-user can only benefit from products addressing their unique concerns. Hopefully this push will 
increase the demand for manufacturing to return to the US, and allow financial security for start-ups, companies and investors alike.

The relation of conceptual design and social interaction is an important issue that influences the future of industrial design management. The Social Web has made astonishing progress the last two years, while advanced manufacturing technology emerges in an endless stream. The results are an extensive amount of accessible data that can promote endless new ideas for innovation. The environmental effect and social moral concept of design, the manufacturing place and method of product, the materials, function and usages of product, as well as abandonment and recovery of product, have become the new connotative meanings of conceptual design. This goes beyond traditional product design.

\section{CONCLUSION}

From the design of product into the design of service, the design of material object into the design of virtual product and the design of service into social interactions... a completely new mode of industrial design is emerging. The whole world is moving into the era of accelerated digitalization and extended collaboration. Then, maybe we should be training a new breed of design called Social" Design? Well, that's sounds like Anthropology meets Human Factors".

For industrial design research, the adornment-wit model paves the way for new empirical investigations that will be presented in later papers. Are there types of objects where wit is more frequent and more acceptable? Is it true for high tech products with interactive features? Are luxury furniture and goods more conservative and dominated by adornment?

Can we find wit in more common products? What is the contribution of wit to the vitality of industrial design in contemporary societies? What are the conditions of commercial success in each case? Do schools of design prepare equally their students to both logics? The work programmed drawn up at the beginning of the article can therefore be based on solid theoretical and empirical grounds. Modern industrial design only seemed to be mysterious and to lack its own reasoning because we did not have a theoretical framework with which to study design activities. A second step was to relate this to the intellectual traditions of rhetoric. We hope to have shown that they provide a very powerful analytical and critical framework. This framework helps set industrial design research into an intellectual project of wide theoretical and cultural significance.

We may now return to the introductory question of Marc Augé: what is that meaning created by design"? What we have learned is that industrial design is neither applied Art serving commercial purposes, nor an emotional and sensitive form of engineering. As a design activity in its own right, industrial design deconstructs the meaning of ordinary objects and explores its transformation by adornment and wit. In this context, it can rightfully claim its own research and teaching environment in line with the most demanding academic traditions.

\section{REFERENCES}

[1] Beverland, M. B, Managing the design innovation-brand marketing interface: Resolving the tension between artistic creation and commercial imperatives. Journal of Product Innovation Management 22 (2): 193-207, 2005.

[2] Goffin, K., and U. Koners, Tacit knowledge, lessons learnt, and new product development. Journal of Product Innovation Management 28 (2): 300-318, 2011.

[3] Pietro Micheli, Joe Jaina, Keith Goffin,Fred Lemke and Roberto Verganti, Journal of Product Innovation Management,Volume 29 Issue 5, pages 687-704, 2012.

[4] Hertenstein, J.H., Platt, M.B. and Brown, D.R.,Valuing Design: Enhancing Corporate Performance through Design Effectiveness. Design Management Journal 12 (3): 10-19, 2001.

[5] Dorst K, The core of -design thinking" and its application, Design studies, 32, pp.521-532, 2011.

[6] Gillier, T. and Piat, G, Exploring Over: The Presumed Identity of Emerging Technology. Creativity and Innovation Management, 20: 238-252, 2011

[7] Le Masson P, Hatchuel A, Weil B, The strategic management of innovation and design, Cambridge University Press, 2010.

[8] Tomkinwise C., A taste for practices : unrepressing style in Design thinking, Design Studies, 32, pp. 533-545, 2011.

[9] Sharif Ullah AMM, Mamunur Rashid M, Tamaki Ji, On some unique features of CK theory of design, CIRP Journal of Manufacturing Science and Technology, 5, pp. 55-66, 2011.

[10] O'Marah, K, Make to desire: How new technologies are revolutionizing life cycle management. Achieving Supply Chain Excellence Through Technology. Montgomery Research, San Francisco, CA, 2001.

[11] Thomke, S, Capturing the real value of innovation tools. Sloan Management Rev. 47(2) 24-32, 2006.

[12] Environmental Protection Agency, Electronics Waste Management in the United States Through 2009, U.S. EPA, May, Report EPA No. 530-R-11-002, 2011.

[13] Kwak, M., Kim, H. M., and Thurston, D., Formulating SecondHand Market Value as a Function of Product Specifications, Age and Conditions, ASME J. Mech. Des., 134(3), p. 032001, 2012.

[14] Kumar, V., 101 Design Methods: A Structured Approach for Driving Innovation in Your Organization. Wiley, 2013.

[15] Chitturi, R., Chitturi, P., \& Raghavarao, D. , Design for synergy with brand or price information. Psychology \& Marketing, 27,679$697,2010$.

[16] Landwehr, J. R., Wentzel, D., \& Herrmann, A., The tipping point of design: How product designs and brands interact to affect consumers' preferences. Psychology \& Marketing, 29, 422-433, 2012.

[17] Patrick, V., \& Hagtvedt, H. , Aesthetic incongruity resolution. Journal of Marketing Research, 48, 393-402, 2011.

[18] Reimann, M., Zaichkowsky, J., Neuhaus, C., Bender, T., \& Weber, B., Aesthetic package design: A behavioral, neural, and psychological investigation. Journal of Consumer Psychology, 20, 431-441, 2010.

[19] Westerman, S. J., Gardner, P. H., Sutherland, E. J., White T., Jordan, K., Watts, D., et al., Product design: Preference for rounded versus angular design elements. Psychology \& Marketing, 29, 595-605, 2012. 